\title{
EDUCAÇÃO AMBIENTAL À DISTÂNCIA E O DESENVOLVIMENTO DA CONSCIÊNCIA AMBIENTAL CRÍTICA: UM RELATO DE CASO
}

\author{
Alessandra Aparecida Santos \\ lelex.santos@gmail.com
}

\section{RESUMO}

A discussão sobre o ensino em educação ambiental dentro e fora do ambiente escolar é um importante fator na transmissão de valores de uma cultura de gerações. Nesse sentido, as atividades propostas em educação ambiental no ensino a distância devem estimular a análise de dados, a argumentação e o pensamento reflexivo, para que se instaure o espírito investigativo e crítico do cursista. Neste estudo eu descrevi o desenvolvimento senso crítico em um curso de extensão em educação ambiental na modalidade EAD. Também, avaliei os fatores que influenciaram a apropriação do conhecimento no curso, como a taxa de evasão, o atraso na entrega de atividades, o nível de desempenho. A taxa de evasão apresentada foi de praticamente a metade dos inscritos $(51 \% \mathrm{n}=32)$. O comprometimento foi relativamente baixo com uma proporção de $88 \%$ das atividades entregues por cursista fora do prazo $(n=25)$. O desempenho crítico satisfatório dos cursistas foi maior que o insatisfatório $(n=15)$. Os dados sugerem que o uso de ferramentas como fóruns e chats tendem a ser mais interessantes e frequentes do que aquelas de elaboração de textos opinativos e projetos, provavelmente devido à facilidade de execução das primeiras. Tendo em vista a importância da educação ambiental formando cidadãos críticos e capazes de intervir com eficiência e responsabilidade no ambiente em que vivem, a aprendizagem por projetos e o enfoque no debate parecem ser os melhores caminhos para o sucesso de futuros cursos em educação ambiental e modalidade na à distância.

Palavras-chave: senso crítico, educação ambiental, ensino à distância

\section{ABSTRACT}

The discussion on environmental education inside and outside school is an important factor for transmitting values of a culture of generations. So, on distance learning of environmental education, the proposal of activities must stimulate data analyses, arguing and reflexive thoughts for the establishment of investigative and critical spirit of the student. In this study I described the development of critical sense in a course of environmental education in a distance learning modality. Also, I evaluated the factors that probably influenced knowledge assimilation throughout the course, as the evasion rate, the late delivery of activities and the quality of individual performance. The evasion rate was a little above the half of the class $(51 \%, n=32)$. The students commitment was relative low with a rate of $88 \%$ of activities delivered after the deadline $(n=25)$. Critical performance of the students satisfactory was higher than insatisfactory $(n=15)$. The data suggest that the use of tools like foruns and chats by the students tend to be more frequent than those which require a production of discursive texts and projects, probably due to the easy execution of these first ones. Once the importance of environmental education creating critical citizens who are capable of interfering with efficiency and responsibility at environment, the learning by projects and the focus on the debate may be the greatest paths for the success of future courses on education environment and distance modality.

Keywords: critical sense, environmental education, distance learning 


\section{INTRODUÇÃO}

A reconstrução de uma cultura que preserve o equilíbrio entre o homem e o ambiente depende da variedade de ferramentas de aprendizagem e conscientização disponíveis na sociedade e no sistema educacional. De fato, a educação ambiental na modalidade ensino a distância representa um passo importante em direção à aprendizagem crítica das questões ambientais e de novas posturas para uma sociedade ambientalmente consciente.

Segundo Amaral (2010) cabe ao tutor/professor estimular o espírito crítico, o diálogo e a curiosidade do estudante. As atividades propostas devem estimular a análise de dados, a argumentação e o pensamento reflexivo, bem como favorecer a condição investigativa do estudante. Entretanto, sabemos que os educadores ambientais enfrentam profundos desafios no incentivo do desenvolvimento de valores. Além disso, o estímulo de uma visão global em relação às questões ambientais, bem como um enfoque interdisciplinar que construa saberes, representa outro importante desafio a ser superado pelo tutor (Sorrentino 1998). Nesse aspecto, cursos em educação ambiental devem enfocar seus objetivos no incentivo à adoção de hábitos conscientes e mais saudáveis pelos cursistas. Nesse aspecto, a figura do tutor deve intensificar as reflexões acerca da busca de alternativas sobre problemas locais para a manutenção da qualidade da vida moderna.

A crescente degradação das condições da vida humana tem refletido a atual crise ambiental que vivemos (Jacobi 2003), especialmente frente à série de desastres ecológicos mundiais mais recentes (obs. pess.). O quadro socioambiental que caracteriza as sociedades contemporâneas revela que a interferência humana tem tido impactos cada vez mais complexos sobre a natureza (Jacobi 2003, Mendonça 2000). Assim, é improvável a completa reversão dos crescentes problemas ambientais sem que ocorra uma mudança radical nos sistemas de conhecimento, dos valores e dos comportamentos gerados pela racionalidade e fundamentados no aspecto econômico do desenvolvimento humano (Leff 2001).

Piaget (1976) reforça a necessidade constante de o sujeito transformar o meio em que vive ao conhecer a realidade na qual está inserido. $O$ resultado é a possibilidade de se intervir no padrão de ações sociais através da mudança da cultura ambiental. Tal mudança deve resultar de intensa discussão e troca de experiências do que é adequado e inadequado para a sobrevivência humana. Segundo Mauro Guimarães (2004) a Educação ambiental crítica tem como objetivo promover ambientes educativos de mobilização desses processos de intervenção sobre a realidade e seus problemas socioambientais ao mesmo tempo em que propicia o exercício da cidadania. Nesse aspecto, a educação ambiental tem o sistema de educação formal como uma peça-chave no processo de redução da pobreza ou de desequilíbrio nas relações sociais. Porém, a educação brasileira é altamente seletiva e excludente, sendo que não basta permitir o acesso à educação a todos, mas também criar condições para o real desenvolvimento e aproveitamento da educação como fonte de redução dos acentuados níveis de desigualdade no país (Bigliardi \& Cruz, 2008). Portanto, a educação ambiental na modalidade ensino à distância pode representar uma importante ferramenta do desenvolvimento da consciência ambiental crítica, desde que sejam criados meios que estimulem a capacidade de intervenção consciente sobre o meio por parte dos cursistas. Assim, é possível evitar problemas graves no desenvolvimento do curso como a evasão e baixo aproveitamento das atividades propostas. Neste estudo eu descrevi o desenvolvimento do senso crítico sobre as questões ambientais atuais por estudantes do curso de educação ambiental na modalidade extensão à distância. Também, avaliei os fatores que interferem na apropriação do 
conhecimento ao longo do curso como o atraso na entrega de atividades, o nível de desempenho e a taxa de evasão.

\section{METODOLOGIA}

O curso apresentou o formato de extensão na modalidade à distância e foi desenvolvido pela Universidade Federal de Mato Grosso do Sul/Câmpus de Campo Grande entre outubro/2010 e julho/2011.

Ferramentas de interação e capacitação no ambiente virtual moodle/ufms/ead. As ferramentas disponíveis no ambiente virtual para a capacitação do cursista foram: sala virtual, wiki, bate-papo (chats), fóruns, atividades dicursivas, correio eletrônico, mensagens instantâneas e mural de notícias.

Sala virtual: Esta ferramenta foi proposta para desenvolver teleconferências entre os coordenadores do curso, os tutores e os cursistas, sendo utilizada principalmente como meio de apresentação dos projetos finais.

Wiki: Foi proposta como atividade obrigatória com o intuito de incentivar a interação dos cursistas na elaboração de textos colaborativos.

Bate-papo (chats): Instrumento de auxílio em que o tutor orientava a execução de atividades e sanava as dúvidas. Para tanto os cursistas deveriam se programar e entrar na sala de bate papo nos horários semanais ( $4 \mathrm{~h}$ semanais) previamente definidos pelo tutor.

Fóruns: Ferramenta em que o cursista poderia expor suas idéias provocando e sugerindo alternativas possíveis para os problemas propostos.

Atividades discursivas: As atividades elaboradas na forma de texto poderiam ser feitas a partir do modelo geral enviado previamente pelo tutor ou poderiam apresentar caráter livre, ou seja, sem o modelo. Dois tipos de atividades foram propostas: as obrigatórias e as opcionais para aqueles que quisessem se aprofundar no assunto.

Correio eletrônico: Através desta ferramenta eventuais dúvidas, esclarecimentos específicos e urgentes poderiam ser tratados entre cursistas e tutores.

Mensagens instantâneas: Ferramenta constituída de mensagens curtas entregues instantaneamente ao seu destinatário on line.

Mural de notícias: Essa ferramenta apresentou um formato idêntico a um fórum, porém com o objetivo de expor as notícias mais recentes sobre a educação ambiental para os cursistas de todas as turmas, estimulando o senso crítico e informando eventos importantes na área.

Avaliação do desenvolvimento da aprendizagem. Para avaliar o desempenho dos cursistas eu utilizei três critérios principais: a taxa de evasão, o comprometimento com o curso, nível crítico das argumentações e apresentação do projeto final.

A taxa de evasão é um fator determinante no sucesso ou fracasso da aprendizagem e do curso em si, tendo sido avaliada considerando a proporção do número de alunos que ingressaram, mas não executaram nenhuma atividade ou desistiram ao longo do curso.

O comprometimento do cursista na elaboração e entrega das atividades propostas foi avaliado como um fator de importante influência sobre a apropriação do conhecimento e foi analisado por meio do atraso na entrega das atividades. Para tanto, desconsiderei o número de pessoas que não executaram qualquer atividade proposta ao longo dos módulos.

O nível crítico das argumentações foi avaliado a partir do número de cursistas que além de terem executado as atividades obrigatórias, desenvolveram argumentações de qualidade nas 
tarefas enviadas, as quais foram classificadas em satisfatória e insatisfatória. Todas as atividades desenvolvidas pelos cursistas foram classificadas em satisfatórias e insatisfatórias. O desempenho foi considerado satisfatório quando o cursista apresentou idéias originais, claras e críticas nas atividades propostas, seja fórum ou produção de texto de opinião, ou ainda, se participou de atividades opcionais. Por outro lado, o desempenho foi considerado insatisfatório quando o cursista apresentou argumentações com imprecisão, falta de clareza e coerência, além da ausência de discussão e sugestões para os problemas propostos. Apenas os cursistas que tiveram acesso à plataforma do curso e fizeram pelo menos uma atividade proposta foram considerados na avaliação do desempenho.

A elaboração e apresentação do projeto final foram utilizadas para avaliar principalmente a capacidade de pensar em alternativas/soluções para os problemas ambientais locais mais comuns através de estudos de caso, levantamentos ou projetos ambientais a serem desenvolvidos dentro fora ou das escolas. Esse fator foi avaliado através no número de cursistas que apresentaram trabalhos originais e/ou detalhados apontando os problemas e as respectivas sugestões para solucioná-los. Para avaliar a possível preferência das atividades, eu as classifiquei em texto de opinião e fórum, e utilizei a média de todas as atividades não executadas pelos cursistas que fizeram ao menos uma atividade, mas desistiram do curso.

\section{RESULTADOS}

A turma que orientei apresentou 32 inscritos sendo que desses, sete não chegaram a desenvolver nenhuma atividade e dez desistiram do curso, sendo que apenas 15 completaram todas as atividades finalizando o curso. A taxa de evasão dos cursistas foi relativamente alta (51\% dos cursistas inscritos, $n=32$ ). Em relação ao comprometimento dos cursistas, os prazos fixados previamente para o desenvolvimento das tarefas foram pouco respeitados, sendo que o número de indivíduos que atrasaram na entrega de atividades foi alto $(88 \%$ dos cursistas que desenvolveram pelo menos uma das atividades propostas, $n=25$, Fig. 3). 0 desempenho crítico satisfatório foi maior que o insatisfatório para todos os estudantes que terminaram o curso ( $n=15$; Fig. 1). A média de atividades não executadas foi maior para os textos de opinião do que para os fóruns (média de $19 \pm 3.7$, média de $16 \pm 3.4, n=17$, respectivamente; Fig. 2), o que sugere a preferência do fórum enquanto atividade proposta. Os projetos finais foram elaborados e apresentados em duplas ou trios, sendo que dos oito trabalhos avaliados, três projetos apresentaram originalidade nas propostas de intervenção no meio, pois se tratavam de sugestões para problemas locais, enquanto os outros trabalhos consistiram basicamente em levantamentos e estudos de caso cujas sugestões para os problemas descritos foram pouco detalhadas. 


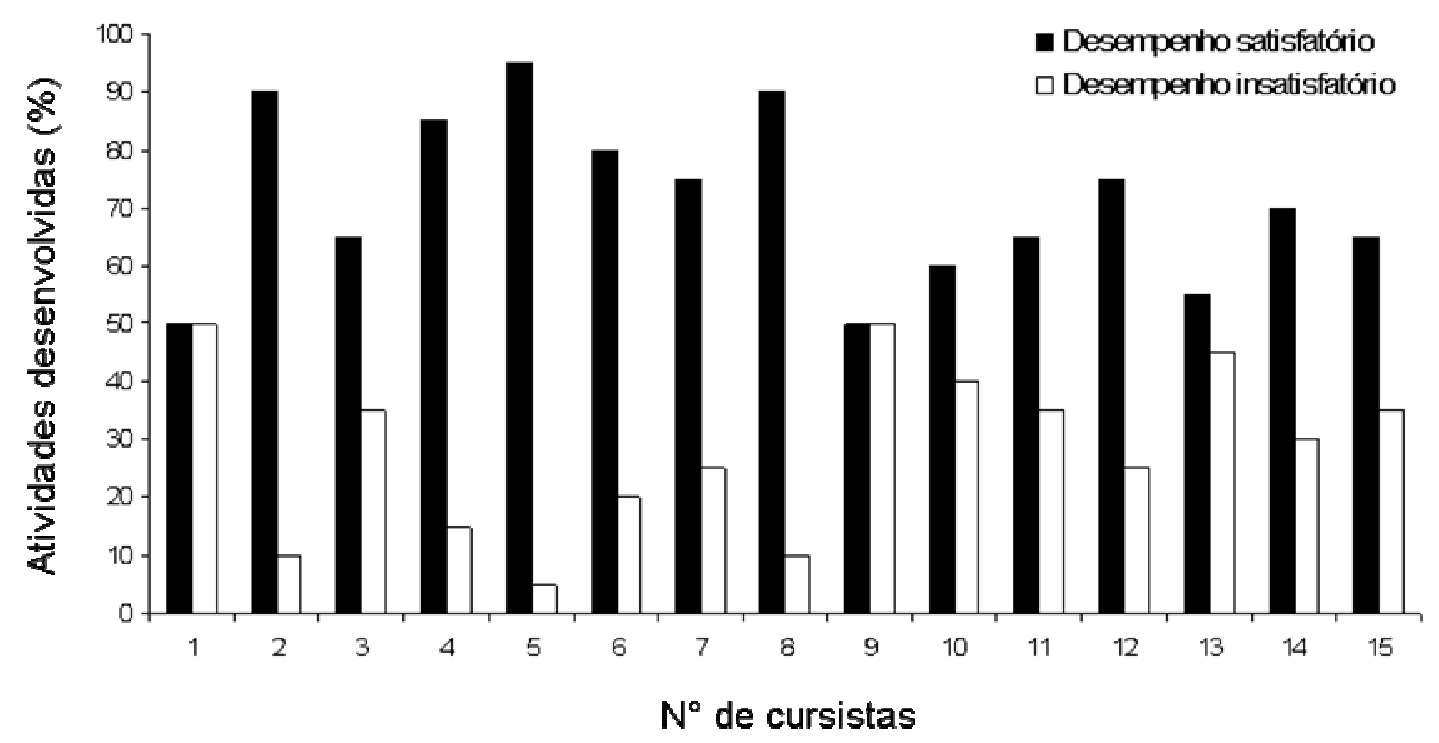

Figura1.Variação no desempenho dos indivíduos que finalizaram o curso em cada uma das atividades obrigatórias.

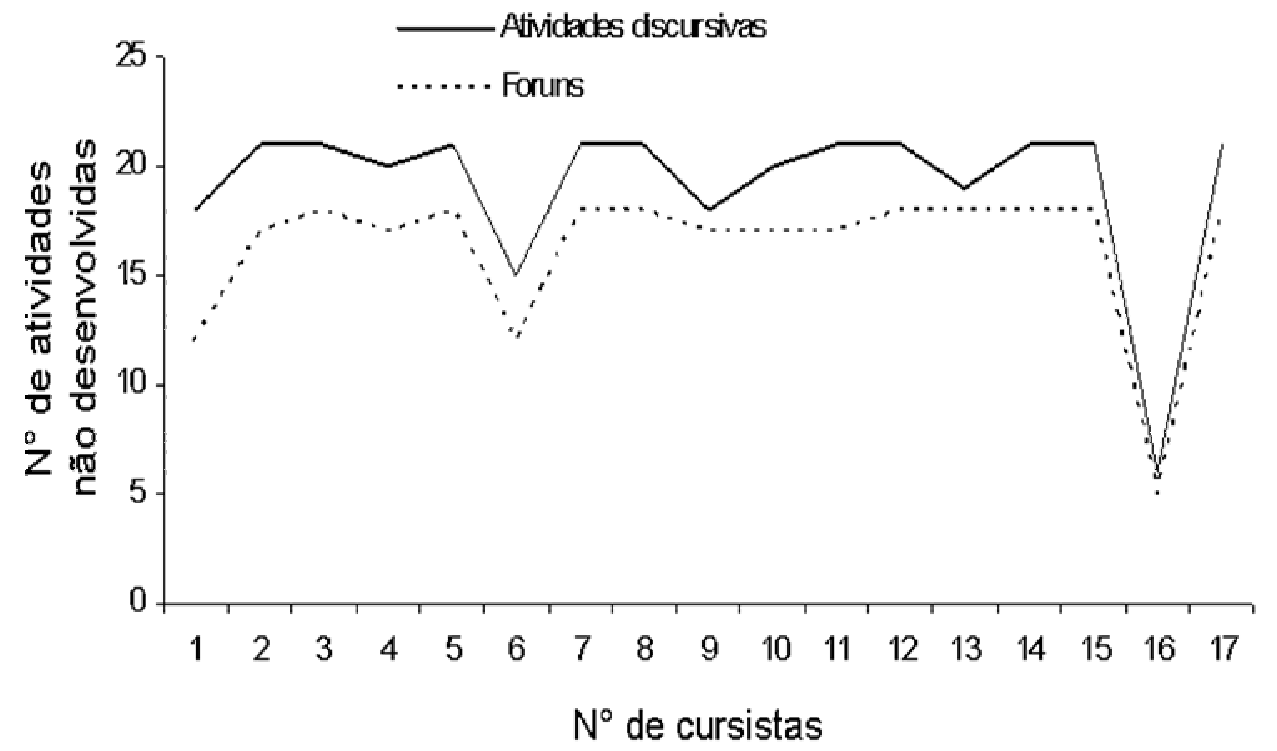

Figura 2. Variação do número de atividades não executadas pelos 17 cursistas que não concluíram o curso. 


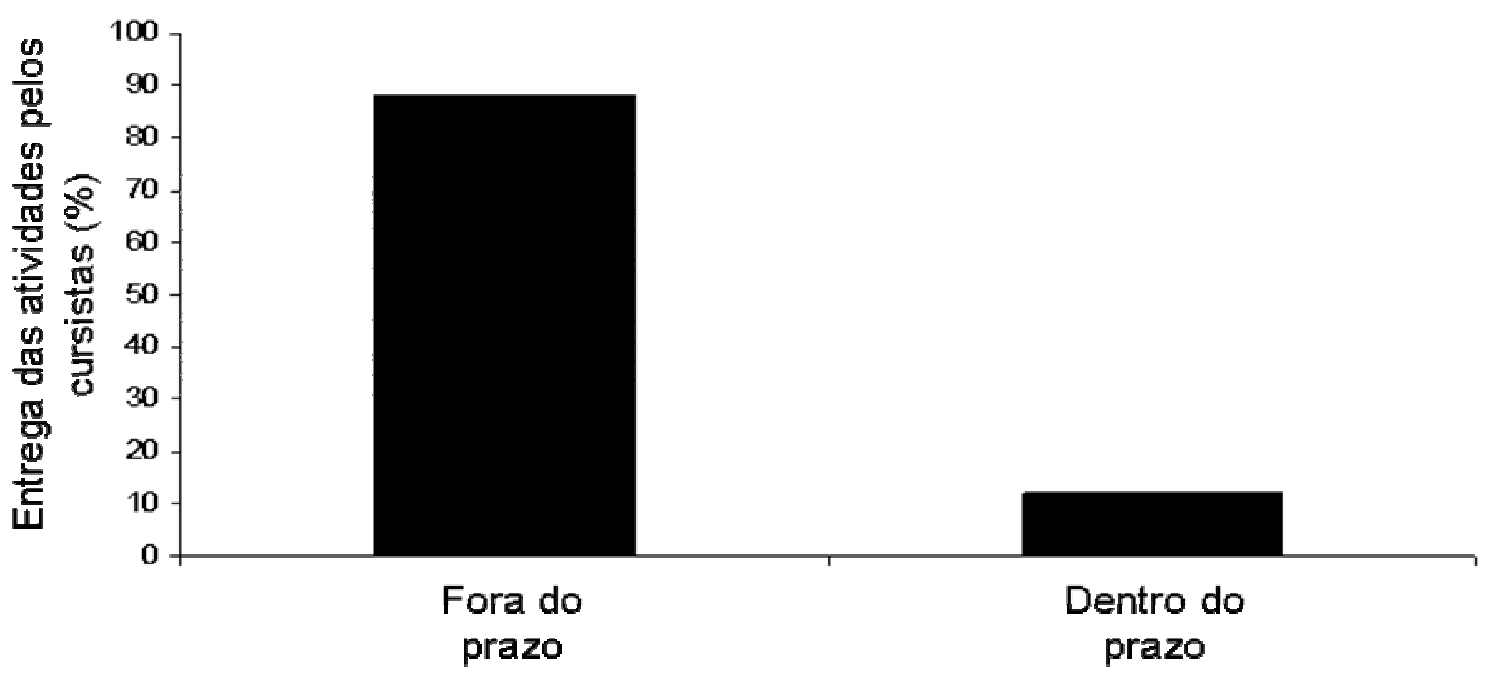

Figura 3. Proporção de cursistas que entregaram as atividades propostas dentro e fora do prazo, $n=25$.

\section{DISCUSSÃO}

Planejar meios de se evitar a evasão para que o número de multiplicadores dos conceitos de educação ambiental se amplie é claramente essencial, tendo em vista a importância da dedicação e persistência para o sucesso de qualquer curso. Neste sentido, os recursos de aprendizagem coletiva como wikis e chats parecem poder transformar técnicas antigas (Amaral 2010), como a entrega de atividades na forma de relatórios, em atuais e mais proveitosas. Atualmente o trabalho em grupo é de suma importância em relação à educação ambiental, tendo em vista que muitas pessoas envolvidas em um mesmo ideal tendem a ter mais força ao tomar decisões. O desenvolvimento do senso crítico representa um fator de elevada relevância a ser considerado em futuros cursos à distância em educação ambiental direcionados à comunidade. Entretanto, poucos cursistas perceberam a real importância de cada uma dessas ferramentas se utilizando pouco delas. Para um desempenho satisfatório em qualquer curso na modalidade EAD a assiduidade é essencial. O envolvimento do cursista com os assuntos discutidos está diretamente ligado à freqüência com que ele acessa e participa das atividades propostas. Entretanto, a participação nas atividades foi diminuindo muito a cada novo módulo, culminando com mais da metade dos cursistas inscritos evadidos. Muitos alegaram problemas pessoais, outros argumentaram em defesa da prioridade de outros cursos que estavam desenvolvendo ou ainda, o trabalho excessivo fora do curso dificultando a entrega de atividades no prazo devido. De fato, o atraso na entrega das atividades também foi alto, sendo que alguns módulos tiveram a data de entrega das atividades prorrogadas de forma a favorecer a sua execução. Tal fato se mostrou ineficiente tendo em vista que sempre os mesmos cursistas atrasaram e mesmo com a prorrogação o desempenho não se elevou para a maioria dos casos. Aparentemente, o perfil do cursista deve ser determinante no seu desempenho em qualquer curso, o que nos remete a refletir na importância de aprimorar os métodos da seleção de estudantes que realmente se comprometam com a educação ambiental.

Segundo Lemos (1996) os objetivos da aprendizagem pelos alunos/cursistas se orientam pela tentativa, comparação e competição. Em um ambiente virtual é objetivo geral aprender e as 
tentativas são pontos chave para que se consiga sedimentar o que é proposto. Se a resposta às atividades por parte do tutor é negativa é necessário que o estudante se envolva o suficiente com a tarefa a ponto de corrigi-la. Muitos cursistas apenas enviaram a primeira versão de seus textos de opinião demonstrando certo nível de negligência em relação ao seu próprio desenvolvimento no curso. A correção das atividades não deve ser vista pelo tutor e cursista como a busca de uma resposta ideal, mas antes, como uma oportunidade de exercitar as habilidades que cada tarefa requer. Por isso, ao se propor uma tarefa em um ambiente virtual, os objetivos devem ser sempre muito claros e se possível, simples.

A comparação parece ser um ato comum ao ser humano mesmo como forma de se situar na sociedade estabelecendo sua função, direitos e deveres dentro dela. Nesse sentido, essa parece ser uma poderosa ferramenta ao longo do processo de aprendizagem por estimular profundamente a competição entre os grupos e indivíduos. Por isso, as atividades coletivas são essenciais em cursos de educação ambiental em que o debate é central. Entretanto, a construção de textos colaborativos (wikis) e conversas coletivas (chats), em que esse ato foi essencial, não tiveram efeito positivo sobre a aprendizagem na turma que orientei quando comparadas às ferramentas de uso individual. Além dessas ferramentas virtuais as atividades de elaboração de textos de opinião também devem ser preparadas de forma a promover a competição estimulando não só o interesse, mas também a dedicação dos cursistas na busca de alternativas para problemas ambientais locais.

O desempenho dos cursistas foi altamente satisfatório para aqueles que se envolveram com as atividades propostas devido à possibilidade de se repensar muitas atitudes rotineiras e ambientalmente incorretas. Por outro lado, percebi que muitos dos cursistas se envolveram pouco participando apenas uma vez das discussões dos fóruns ou enviando textos curtos sem clareza ou consistência crítica. Nesse aspecto, apesar de quase todos os cursistas terem apresentado a maioria de suas atividades satisfatórias (Fig. 1), é importante se buscar um nível de excelência através das atividades propostas. Sabemos que o que lemos não se fixa em nossa memória, na maioria das vezes, se não houver exercício contínuo do assunto e interesse. Assim, é preciso exercitar o que se aprende, debater, investigar para que possamos interferir com responsabilidade no meio à nossa volta a partir do conhecimento adquirido.

Aparentemente, os estudantes preferem as tarefas mais individuais, como a produção de texto opinativo e a participação em fóruns. Esta última é, sem dúvida, uma importante ferramenta para ampliar o debate de questões ambientais da atualidade. Nesse sentido, o enfoque às atividades coletivas de debate é essencial, tendo em vista que é nesse tipo de situação que as pessoas são levadas a pensar com originalidade e respeito tanto ao próximo quanto ao ambiente. Nesse sentido, o fórum atua como uma ferramenta de participação em massa, mas ao mesmo tempo, menos cansativo, dispensando uma elaboração mais formal do texto postado. De fato, os fóruns foram mais utilizados, pois, provavelmente são mais fáceis de serem acessados sem a necessidade de que os colegas de turma estejam on line ao mesmo tempo, bem como a visualização geral das postagens das opiniões do grupo que facilitam as contra-argumentações e o debate de forma organizada. Inevitavelmente, textos mais articulados exigem um padrão de elaboração segundo a norma culta e isso precisa ser trabalhado mais detalhadamente pelo tutor junto aos cursistas, o que pode desmotivá-los pelo tempo despendido nas correções. Consequentemente, a necessidade de postagens muito articuladas pode influenciar a escolha do tipo de atividade que o cursista priorizará evitando as mais longas e escolhendo as mais dinâmicas e de rápida execução. Além disso, a elaboração de atividades discursivas mais objetivas e 
contextualizadas em relação à realidade ambiental brasileira parece ser uma alternativa capaz de despertar um maior interesse na execução das tarefas.

O curso apresentou um enfoque diretamente ligado à comunidade escolar, como professores e funcionários escolares, mas também esteve voltado para a comunidade aberta em geral. Nesse aspecto, a mudança de atitude e do ato de pensar é a condição que deve trazer significado à linha de trabalho do curso. Na apresentação final bem como na atividade de intervenção do meio pude constatar o impacto do curso na mudança de valores devido ao entusiasmo com que os estudantes falavam de seus projetos. Cada cursista apresentou seus trabalhos resultantes da pesquisa sobre a região em que moravam e expuseram formas de se solucionar problemas comuns com alternativas práticas e inovadoras. Entre as alternativas levantadas, algumas foram realmente interessantes como a produção de sabão para reaproveitar o óleo de cozinha A alternativa de reciclagem de substâncias orgânicas foi a mais original apresentada em nos trabalho finais. Apesar de sabermos que a maior alternativa pode ser a educação econômica no consumo dos recursos mais diversos, o reaproveitamento desses recursos pode ser também determinante em direção a uma sociedade mais responsável e sustentável. De fato, todos os trabalhos e discussões dos módulos esbarraram sempre no consumismo como sendo o maior causador de um ambiente insalubre. De posse dessa informação, poderemos direcionar nossos esforços na elaboração de cursos em educação ambiental que enfoquem mais intensamente a necessidade do cursista se transformar como um ser que vê a economia como forma de preservar o maior bem coletivo: o meio em que vive.

\section{CONCLUSÕES}

O enfoque na elaboração de projetos aparentemente é uma das formas mais positivas de se ensinar no ensino a distância, pois o cursista não só tem domínio sobre a construção do seu conhecimento, mas também tem liberdade para produzir uma alternativa criativa para os problemas dos locais em que vive. Assim, o cursista passa a se valorizar como um ser que intervêm positivamente no mundo a sua volta gerando alternativas saudáveis para manutenção do seu meio e das próximas gerações. A falta de originalidade de alguns dos projetos avaliados ocorreu possivelmente devido à necessidade de cada situação ser melhor acompanhada pelo tutor. Tal fato ocorreu porque nesta fase muitos cursistas não aceitaram minha orientação ou não atenderam aos prazos de planejamento do projeto. Penso que o ato de planejar requer tempo e dedicação, sendo que o uso inadequado de ambos pode levar qualquer projeto ao fracasso. Em um curso à distância a orientação do estudante é a peça fundamental no do seu desenvolvimento porque o estudo pode ser maximizado para atender a finalidade desejada no processo de aprendizagem. Uma pessoa que estuda sozinha sente muito mais dificuldade do que quando é orientada a estudar os assuntos necessários a atingir seus objetivos. Porém, se o próprio cursista negligenciar esse fator estará certamente favorecendo seu próprio insucesso.

A educação ambiental preserva em seu estado latente a condição de promoção de uma aprendizagem baseada no senso crítico e na responsabilidade social. Para atingir tais princípios no ensino à distância é essencial promover uma interação cursista-cursista e cursista-tutor mais dinâmica. Além disso, se faz necessário o enfoque à busca individual do conhecimento. Nesse sentido, os projetos e os estudos de caso podem ser valiosas ferramentas enquanto atividades propostas para promover não só a dinâmica do curso, diminuindo assim as taxas de evasão, mas 
também para favorecer a apropriação do conhecimento e desenvolvimento do senso crítico do estudante.

\section{REFERÊNCIAS BIBILOGRÁFICAS}

AMARAL, M. C. S. A Educação à distância na reconstrução das competências docentes. Revista Signorelli, Rio de Janeiro, p. 35-46, 2010.

BIGLIARDI, R. V.; Cruz, R. G. Educação ambiental no ensino formal: reflexões acerca de uma práxis educativa emergente. Revista didática sistêmica, Rio Grande, v. 8, p. 1-12, 2008.

JACOBI, P. Educação ambiental, cidadania e sustentabilidade. Cadernos de pesquisa, São Paulo, p.189-205, 2003.

LEFF, E. Epistemologia ambiental. São Paulo, Cortez, 2001.

LEMOS, M. Student's and teacher's goals in classrooms. Learning and instruction,Cidade do Porto, Portugal, v. 6, p. 151-171, 1996.

MENDONÇA, F. Aspectos da interação clima-ambiente-saúde humana: da relação sociedadenatureza à (in) sustentabilidade ambiental. Curitiba, R. RA'EGA, v. 4, p. 85-99, 2000.

GUIMARÃES, M. Identidades da educação ambiental brasileira. Ministério do meio ambiente, Brasília, p. 25-34, 2004.

PIAGET, J. A equilibração das estruturas cognitivas: problema central do desenvolvimento. Rio de Janeiro, Zahar, 1976.

SORRENTINO, M. De Tbilisi a Tessaloniki, a educação ambiental no Brasil, São Paulo, Brasil. In: JACOBI, P.; CASCINO, F.; OLIVEIRA, J. F. Educação, meio ambiente e cidadania: reflexões e experiências, São Paulo, p. 27-32, 1998. 